\title{
A review and meta-analysis of the enemy release hypothesis in plant-herbivorous insect systems
}

\author{
Kim Meijer ${ }^{1,2}$, Menno Schilthuizen ${ }^{1,3}$, Leo Beukeboom ${ }^{1}$, Christian Smit ${ }^{\text {Corresp. } 1}$ \\ ${ }^{1}$ Groningen Institute for Evolutionary Life Sciences, University of Groningen, Groningen, The Netherlands \\ 2 Altenburg \& Wymenga Ecological Consultants, Veenwouden, the Netherlands \\ 3 Endless Forms group, Naturalis Biodiversity Center, Leiden, Netherlands \\ Corresponding Author: Christian Smit \\ Email address: c.smit@rug.nl
}

A suggested mechanism for the success of introduced non-native species is the enemy release hypothesis (ERH). Many studies have tested the predictions of the ERH using the community approach (native and non-native species studied in the same habitat) or the biogeographical approach (species studied in their native and non-native range), but results are highly variable, possibly due to large variety of study systems incorporated. We therefore focused on one specific system: plants and their herbivorous insects. We performed a systematic review and compiled a large number (68) of datasets from studies comparing herbivorous insects on native and non-native plants using the community or biogeographical approach. We performed a meta-analysis to test the predictions from the ERH for insect diversity (number of species), insect load (number of individuals) and level of herbivory for both the community and biogeographical approach. For both the community and biogeographical approach insect diversity was significantly higher on native than on non-native plants. Insect load tended to be higher on native than nonnative plants at the community approach only. Herbivory was not different between native and non-native plants at the community approach, while there was too little data available for testing the biogeographical approach. Our meta-analysis generally supports the predictions from the ERH for both the community and biogeographical approach, but also shows that the outcome is importantly determined by the response measured and approach applied. So far, very few studies apply both approaches simultaneously in a reciprocal manner while this is arguably the best way for testing the ERH. 
1 A review and meta-analysis of the enemy release hypothesis in plant - herbivorous insect

2 systems

3 Kim Meijer $^{1,2}$, Menno Schilthuizen ${ }^{1,3}$, Leo W. Beukeboom ${ }^{1}$, Christian Smit ${ }^{1 * *}$

4 1. Groningen Institute for Evolutionary Life Sciences (GELIFES), University of Groningen, P.O.

5 Box 11103, 9700 CC Groningen, the Netherlands

6 2. Altenburg \& Wymenga Ecological Consultants, P.O. Box 32, 9269 ZR Veenwouden, the

7 Netherlands

8 3. Endless Forms group, Naturalis Biodiversity Center, Darwinweg 2, 2333 CR Leiden, the

9 Netherlands

** Corresponding author: c.smit@,rug.nl

\section{Abstract}

A suggested mechanism for the success of introduced non-native species is the enemy release hypothesis (ERH). Many studies have tested the predictions of the ERH using the community approach (native and non-native species studied in the same habitat) or the biogeographical approach (species studied in their native and non-native range), but results are highly variable, possibly due to large variety of study systems incorporated. We therefore focused on one specific system: plants and their herbivorous insects. We performed a systematic review and compiled a large number (68) of datasets from studies comparing herbivorous insects on native and nonnative plants using the community or biogeographical approach. We performed a meta-analysis to test the predictions from the ERH for insect diversity (number of species), insect load (number of individuals) and level of herbivory for both the community and biogeographical approach. For both the community and biogeographical approach insect diversity was significantly higher on native than on non-native plants. Insect load tended to be higher on native than non-native plants at the community approach only. Herbivory was not different between native and non-native plants at the community approach, while there was too little data available for testing the biogeographical approach. Our meta-analysis generally supports the predictions from the ERH for both the community and biogeographical approach, but also shows that the outcome is importantly determined by the response measured and approach applied. So far, very few studies apply both approaches simultaneously in a reciprocal manner while this is arguably the best way for testing the ERH. 


\section{Introduction}

Understanding what determines the success of non-native species in natural environments is a key theme in biological invasion research. The Enemy Release Hypothesis (ERH) (Williamson, 1996) forms an important explanation for the success of non-native species: they suffer less from natural enemies (predators, parasites and herbivores) than native species for two main reasons: 1) non-native species may have been introduced without their natural enemies, and 2) potential enemies may not yet have colonized and/or adapted to the novel species. These predictions from the ERH have been tested many times in both animals and plants, using either the community approach (studying native and non-native species in the same habitat or community) or the biogeographical approach (studying the same species in their native and introduced habitat). However, the outcomes of these studies are highly variable (Keane and Crawley, 2002; Jeschke et al., 2012) and sometimes even contradicting each other. For instance, Colautti et al. (2004) showed that most of the reviewed studies (15 out of 25) found support for the ERH, while six found no support and five found results opposite to the prediction of the ERH (one study found both support for and against the ERH). They therefore conclude that there is no simple relationship between enemy release and the success of non-native species.

Possibly, the contradictory results are due to the large variety of study systems incorporated. If so, one would expect less variability when focussing on a more specific system. Indeed, two reviews with such a narrower focus provided more robust results with general support for the ERH. Torchin et al. (2003) reviewed the parasite load of 26 animal host species (including molluscs, crustaceans, fishes, birds, mammals, amphibians and reptiles), using the biogeographical approach, and found twice as many parasite species on animals in their native habitat, compared to the introduced habitat. Liu and Stiling (2006) reviewed ERH studies in plant - herbivore insect systems and similarly found clear support for the ERH. However, these latter results should be interpreted with care for two reasons. First, the studies reviewed only investigated a limited number of plant species. Second, data for this review were obtained using very different methods (ranging from limited anecdotal observations to many years of field data). Hence, for a proper review of the ERH one would best focus on studies of a specific system, which apply comparable study approaches and methodologies, and with sufficiently large numbers of species studied. 
We performed a review of the ERH using one type of study system, namely plants and their insect herbivores. We compiled a large number (68) of datasets that use the community or biogeographic approach, incorporating in total more than 700 plant species. With this dataset we performed a meta-analysis for both approaches to test the predictions of the ERH that the insect diversity, insect load and level of herbivory are higher on native host plants (or in native habitats) than on non-native host plants (or in non-native habitats).

\section{Materials and methods}

\section{Data collection}

The two main methods used to study the effect of the ERH - the community approach and the biogeographical approach - each have their benefits and disadvantages. The benefit of the community approach (studying different native and non-native species in the same community) is that all species are studied within the same environment. However, the disadvantage is that taxonomically very different plant species are compared, often even from different families. Since the diversity and numbers of herbivorous insects (hereafter insects) between plant taxa may vary greatly (Agrawal and Kotanen, 2003), the choice of plants studied can greatly influence the outcome of study. Probably the best way to use the community approach is to compare native and introduced species from the same genus, as some studies have done (Auerbach and Simberloff, 1988; Kennedy and Southwood, 1984; Leather, 1986; Proches et al., 2008; Sugiura, 2010), or to encompass a substantial representation of a region's entire flora. With the biogeographical approach (comparing the same plant species in both native and novel habitat) this problem of using taxonomic different plant species is avoided, but the community in which the species are studied may be very different. From here onwards, when considering the biogeographical approach, we will refer to native species for species growing in their native area and to nonnative species for species growing in their introduced area. In line with the reviewed papers, we here use a rather broad definition of success of non-native species that includes species that successfully establish and (rapidly) expand in the novel environment, often - but not necessarily - becoming pest species (i.e. resulting in large negative economic or ecological impact (sensu Williamson, 1996)).

We searched Web of Science for relevant studies using single or a combination of the following keywords: native, non-native, insect, plant, introduced, non-indigenous, exotic, invasive. Furthermore, we used cross-referencing to find additional articles referring to these retrieved studies. In total, we found 68 datasets in 44 articles published between 1974 and 2015, 
studying one of the following variables: number of insect species (measure of diversity, 33 datasets, Table 1), number of insect individuals (measure of insect load, 18 datasets, Table 2) and level of herbivory - predominantly scored as number / percentage of leaves with herbivore damage (including leaf mining), percentage herbivore damage per leaf, or differences in leaf biomass (17 datasets, Table 3). For all datasets, the means and standard deviations of the abovementioned variables were taken (if only standard error was given, standard deviation was calculated based on standard error and sample size), as well as the number of plant species for native and non-native plant species. We excluded eight datasets from the analyses on the number of insect species (Clement, 1990; Jobin et al., 1996; Johnson et al.,1992; Lindelöw and Björkman, 2001; Moran, 1980; Morrow and Lamarche, 1978; Strong et al., 1984; Tewksbury, 2002; Waloff, 1966), as in these eight studies the data collection of the insects on native plants was done during a different study and/or using a different method than the data collection of the insects on non-native plants. One of the datasets (Table 2, dataset 42) was collected by one of the authors (KM) in 2009 and is here reported for the first time. Native and non-native plant species were sampled for herbivore insects in three nature areas in the North of the Netherlands that are quite similar in tree species composition and land-use history, and within a $15 \mathrm{~km}$ radius (Noordlaarder Bos $53.117^{\circ} \mathrm{N}, 6.644^{\circ} \mathrm{E}$; Vosbergen $53.141^{\circ} \mathrm{N}, 6.583^{\circ} \mathrm{E}$; Mensingebos $53.123^{\circ} \mathrm{N}$, $6.436^{\circ} \mathrm{E}$ ). Eight native plants (Betula pendula, Frangulus alnus, Lonicera periclymenum, Populus alba, Prunus avium, Prunus padus, Quercus robur, Sorbus aucuparia) and four nonnative plant species (Amelanchier spec., Prunus serotina, Quercus rubra, Robinia pseudoacacia) were sampled. To standardize data collection, we selected low hanging branches (up till $2 \mathrm{~m}$ high) of at least $1 \mathrm{~m}$ long that were shaken for $10 \mathrm{~s}$ above a $1 \mathrm{~m}^{2}$ sheet, and counted the number of herbivore insects in the sheet. All other collected functional groups such as predatory or omnivorous insects were discarded. Samples were taken on average 8.25 times per plant species. The data of datasets 1 and 47 could not be extracted directly from the articles (Agrawal et al., 2005; Zuefle et al., 2008). Anurag Agrawal kindly provided us with the raw data of dataset 1, and Marion Zuefle provided us with a copy of her thesis (Zuefle, 2006) which contained the raw data of dataset 47 . We derived the data of datasets 7, 8, 38, 55, 58, 61, 65-68 from the figures in the articles (Adams et al., 2008; Cripps et al., 2010; Vilà et al., 2005; Hartly et al., 2010; Harvey et al., 2015; Lieurance and Cipollini, 2013; Lombardero et al., 2008; Wolfe, 2002).

\section{$\underline{\text { Data analysis }}$}


126 For all datasets the mean, standard deviation, and number of plant species were taken for native

127 and for non-native plants. The mean difference (mean of native plants / mean of non-native

128 plants) was calculated and is shown in Tables 1-3. Then, for each group of datasets a meta-

129 analysis was done using the R package metafor (Viechtbauer 2010) [Random-effects model;

130 model specification: Hedges estimator (Hegdes g)]. Datasets which contained either only one

131 native and/or only one non-native plant species could not be used and were excluded from the

132 analysis. Since all datasets on the level of herbivory using the biogeographical approach studied

133 only one plant species, it was not possible to perform a meta-analysis on these datasets. For each

134 dataset the standardized mean difference and 95\% confidence interval were calculated, and for

135 each group of datasets the overall standardized mean differences and $95 \%$ confidence interval

136 was calculated and tested (Tables 1-3). We report the results for the number of insect species,

137 number of insect individuals and level of herbivory for each approach separately (community and

138 biogeographical approach).

139 Results

140 Number of insect species

141 Community approach

142 In total 22 datasets (261 native and 168 non-native plant species) were found that used the

143 community approach to study differences between native and non-native plants in the number of

144 insect species. Most studies (19) found more insect species on native than on non-native plant

145 species, two found the opposite, and one found no differences. Six of the datasets consisted of

146 only one native and/or only one non-native plant species. These datasets could not be included in

147 the meta-analysis. The analysis of the remaining 16 datasets (256 native and 162 non-native plant

148 species) showed significantly higher numbers of insect species on native than on non-native plant

149 species $(\mathrm{z}=6.16, P<0.001$, Table 1, Fig. 1a).

\section{Biogeographical approach}

Eleven datasets (25 plant species) were found using the biogeographical approach to study differences between plants growing in their native and non-native range. All of these datasets showed higher numbers of insect species in the native than in the non-native range, but all consisted of low numbers of plant species studied. Seven datasets studied only one plant species, the other four datasets studied two species (3 datasets) and 12 (one dataset). These last four datasets (containing more than one plant species) were used for the meta-analysis, which showed 
157 a non-significant trend that plants growing in their native range contained more insect species 158 than when growing in their non-native range $(\mathrm{z}=1.75, P=0.08$, Table 1 , Fig. $1 \mathrm{a})$.

159 Number of insect individuals

160 Community approach

161 Fourteen datasets (94 native and 101 non-native plant species) used the community approach to

\section{Biogeographical approach}

Four datasets (29 plant species) were found that used the biogeographical approach to study the differences in the number of insect individuals between plants growing in their native and nonnative range. Three datasets showed higher numbers of insect individuals on plants growing in their native than their introduced range, one dataset showed the opposite result. Overall, the numbers of insect individuals was significantly higher on plants growing in their native than their introduced range $(\mathrm{z}=2.14, P=0.03$, Table 2, Fig. $1 \mathrm{~b})$.

\section{Level of herbivory}

\section{Community approach}

Thirteen datasets (102 native and 104 non-native plant species) were found that used the community approach to study the differences in the level of herbivory between native and nonnative plant species. Ten datasets found higher levels of herbivory on native than on non-native plant species, three datasets found the opposite. Eight of these datasets (96 native and 99 nonnative species) could be used for the meta-analysis, showing no significant difference in the level of herbivory between native and non-native plant species $(z=0.996, p=0.32$, Table 3, Fig. 1c).

\section{Biogeographical approach}

Four datasets were found that used the biogeographical approach to study the differences in the level of herbivory between plants growing in their native and their non-native range. All four 
186

187 188

datasets showed higher levels of herbivory when plants were growing in their native range. Unfortunately, all four datasets consisted of only one plant species studied, and therefore it was not possible to perform a meta-analysis on these datasets.

\section{Discussion}

Regardless of the applied approach (community or biogeographical), the results of this metaanalysis indicate that native plants contain more insect species than non-native plant species do. Results for insect load and level of herbivory point in the same direction, but differences between native and non-native plants were only marginal or not significant, depending on the applied approach (community or biogeographical approach). Hence, our results are relatively consistent and, at least partly, in line with the predictions of the ERH. The narrower focus on a specific study system - here: plants and their herbivorous insects - may have helped to reduce the variability and contradictory results that others previously encountered (e.g. Colautti et al. (2004)).

Our finding that non-native plants contained fewer herbivorous insect species than native plants can best be explained by the high level of specialization of the majority of herbivorous insects. Most herbivorous insects are extreme specialists, adapted to feeding on only one plant genus (monophage) or one plant species (strict monophage) (Thompson, 1994). Even the more generalist species often consist of locally specialized populations, races or even sibling species, e.g. the ermine moth (Lepidoptera) Yponomeuta padellus L. complex feeding on a various Rosaceae species (Menken, 1996). Most species of phytophagous insects appear to have speciated due to sequential evolution (Miller and Wenzel 1995).

Our results show that both insect load and herbivory levels on non-native plants are not or only marginally - different from those on native plants. In fact, it may be very advantageous for herbivorous insects, even monophages, to shift hosts from native to non-native plants as this novel environment is relatively free of competitors. Indeed, host shifts from native to non-native plants by specialist herbivorous insects have been reported. The most famous example is the host shift by the apple maggot fly Rhagoletis pomonella Walsh (Diptera: Tephritidae) from the native hawthorn (Crataegus spp.) to apple (Malus sylvestris) after the introduction of apple into North America some 400 years ago (Bush, 1969; McPheron et al., 1988). A more recent example is the host shift by the leaf beetle Gonioctena quinquepunctata from native Sorbus aucuparia to Prunus serotina in Western-Europe, leading to (weak) host-specific differentiation in the beetle 
populations (Schilthuizen et al., 2016). With the increasing number of established non-native plants it is to be expected that other native herbivorous insects will follow over time.

With time since arrival in a novel environment also the number of insect species per nonnative plant is expected to increase. Shortly after arrival, only very few insect species will be able to shift host plant, resulting in lower numbers of insect species and/or a lower insect load (number of insects) feeding on non-native plants. However, over time, these numbers may increase, as evidenced by the study of Brändle et al. (2008). Although we were not able to take into account the time since arrival of non-native plants in this study, it would be very interesting to study how this affects the outcome of such a meta-analysis.

Almost all studies we reviewed used a 'one-way' approach: studies using the community approach that compared native and non-native plants in one habitat - but not reciprocally, and studies using the biogeographical approach that compared plants in their native and non-native habitat, but - again - not in a reciprocal way. Using only one of the one-way approaches is likely to result in either over- or underestimation of the differences between native and non-native plants (Meijer et al., 2015). Using both approaches simultaneously in a reciprocal way is arguably the best method for testing the predictions from the ERH, but despite the numerous studies performed on the ERH, very few studies have so far applied this method.

\section{Acknowledgements}

We would like to thank Anurag Agrawal and Marion E. Zuefle, who provided us with the raw data of their research.

\section{References}

Adams, J.M., Fang, W., Callaway, R.M., Cipollini, D. \& Newell, E. (2008) A cross-continental test of the Enemy Release Hypothesis: leaf herbivory on Acer platanoides (L.) is three times lower in North America than in its native Europe. Biological Invasions, 11, 1005-1016.

Agrawal, A.A. \& Kotanen, P.M. (2003) Herbivores and the success of exotic plants: a phylogenetically controlled experiment. Ecology Letters, 6, 712-715.

Agrawal, A.A., Kotanen, P.M., Mitchell, C.E., Power, A.G., Godsoe, W. \& Klironomos, J. (2005) Enemy release? An experiment with congeneric plant pairs and diverse above- and belowground enemies. Ecology, 86, 2979-2989.

Auerbach, M. \& Simberloff, D. (1988) Rapid leaf-miner colonization of introduced trees and shifts in sources of herbivore mortality. Oikos, 52, 41-50. 
248

249

250

251
Brändle, M., Kühn, I., Klotz, S., Belle, C. \& Brandl, R. (2008) Species richness of herbivores on exotic host plants increases with time since introduction of the host. Biodiversity Research, 14, 905-912.

Bush, G.L. (1969) Sympatric host race formation and speciation in frugivorous flies of genus Rhagoletis (Diptera: Tephritidae). Evolution, 23, 237-251.

Bürki, C. \& Nentwig, W. (1997) Comparison of herbivore insect communities of Heracleum sphondylium and H. mantegazzianum in Switzerland (Spermatophyta: Apiaceae). Entomologia Generalis, 22, 147-155.

Carpenter, D. \& Cappuccino, N. (2005) Herbivory, time since introduction and the invasiveness of exotic plants. Journal of Ecology, 93, 315-321.

Cincotta, C.L., Adams, J.M. \& Holzapfel, C. (2008) Testing the enemy release hypothesis: a comparison of foliar insect herbivory of the exotic Norway maple (Acer platanoides L.) and the native sugar maple (A. saccharum L.). Biological Invasions, 11, 379-388.

Clement, S.L. (1990) Insect natural enemies of yellow starthistle in Southern Europe and the selection of candidate biological-control agents. Environmental Entomology, 19, 1882-1888.

Colautti, R.I., Ricciardi, A., Grigorovich, I.A. \& MacIsaac, H.J. (2004) Is invasion success explained by the enemy release hypothesis? Ecology Letters, 7, 721-733.

Cripps, M.G., Edwards, G.R., Bourdôt, G.W., Saville, D.J., Hinz, H.L. \& Fowler, S.V. (2010)

Enemy release does not increase performance of Cirsium arvense in New Zealand. Plant Ecology, 209, 123-134.

Cripps, M.G., Schwarzlander, M., McKenney, J.L., Hinz, H.L. \& Price, W.J. (2006) Biogeographical comparison of the arthropod herbivore communities associated with Lepidium draba in its native, expanded and introduced ranges. Journal of Biogeography, 33, 2107-2119.

Engelkes, T., Wouters, B., Bezemer, T.M., Harvey, J.A. \& Putten, W.H. van der (2012) Contrasting patterns of herbivore and predator pressure on invasive and native plants. Basic and Applied Ecology, 13: 725-734.

Fenner, M. \& Lee, W.G. (2001) Lack of pre-dispersal seed predators in introduced Asteraceae in New Zealand. New Zealand Journal of Ecology, 25, 95-99.

Goeden, R.D. (1974) Comparative survey of phytophagous insect faunas of Italian thistle, Cardus pycnocephalus, in Southern-California and Southern Europe relative to biological weedcontrol. Environmental Entomology, 3, 464-474.

Goßner, M., Gruppe, A. \& Simon, U. (2005) Aphidophagous insect communities in tree crowns of the neophyte Douglas-fir [Pseudotsuga menziesii (Mirb.) Franco] and Norway spruce (Picea abies L.). Journal of Applied Entomology, 129, 81-88.

Goßner, M., Liston, A. \& Späth, J. (2007) Sawflies in the crowns of native and exotic trees, sampled with flith-interception traps in southern Germany (Hymenoptera: Symphyta). Entomologia Generalis, 30, 273-282. 
285

286

287

288

289

290

291

292

293

294

295

296

297

298

299

300

301

302

303

304

305

306

307

308

309

310

Hartley, M.K., Rogers, W.E. \& Siemann, E. (2010) Comparisons of arthropod assemblages on an invasive and native trees: abundance, diversity and damage. Arthropod-Plant Interactions, 4, 237-245.

Harvey, K.J., Nipperess, D.A., Britton, D.R. \& Hughes, L. (2015) Comparison of invertebrate herbivores on native and non-native Senecio species: Implications for the enemy release hypothesis. Austral Ecology, 40, 503-514.

Heard, M.J. \& Sax, D.F. (2013) Coexistence between native and exotic species is facilitated by asymmetries in competitive ability and susceptibility to herbivores. Ecology Letters, 16, 206-213.

Helden, A.J., Stamp, G.C. \& Leather, S.R. (2012) Urban biodiversity: comparison of insect assemblages on native and non-native trees. Urban Ecosystems, 15, 611-624.

Hill, S.B. \& Kotanen, P.M. (2010) Phylogenetically structured damage to Asteraceae: susceptibility of native and exotic species to foliar herbivores. Biological invasions, 12, 33333342 .

Jeschke, J., Aparicio, L.G., Haider, S., Heger, T., Lortie, C., Pyšek, P. \& Strayer, D. (2012)

Support for major hypotheses in invasion biology is uneven and declining. NeoBiota, 14, 1-20.

Jobin, A., Schaffner, U. \& Nentwig, W. (1996) The structure of the phytophagous insect fauna on the introduced weed Solidago altissima in Switzerland. Entomologia Experimentalis et Applicata, 79, 33-42.

Johnson, J.B., Mccaffrey, J.P. \& Merickel, F.W. (1992) Endemic phytophagous insects associated with yellow starthistle in Northern Idaho. Pan-Pacific Entomologist, 68, 169-173.

Keane, R.M. \& Crawley, M.J. (2002) Exotic plant invasions and the enemy release hypothesis. Trends in Ecology \& Evolution, 17,164-170.

Kennedy, C.E.J. \& Southwood, T.R.E. (1984) The number of species of insects associated with British trees: a re-analysis. Journal of Animal Ecology, 53, 455-478.

Leather, S.R. (1986) Insect species richness of the British rosaceae: the importance of host range, plant architecture, age of establishment, taxonomic isolation and species-area relationships. Journal of Animal Ecology, 55, 841-860.

Lieurance, D. \& Cipollini, D. (2013) Exotic Lonicera species both escape and resist specialist and generalist herbivores in the introduced range in North America. Biological Invasions, 15, 17131724.

Lindelöw, A. \& Björkman, C. (2001) Insects on lodgepole pine in Sweden - current knowledge and potential risks. Forest Ecology and Management, 141, 107-116.

Liu, H. \& Stiling, P. (2006) Testing the enemy release hypothesis: a review and meta-analysis. Biological Invasions, 8, 1535-1545.

Liu, H., Stiling, P. \& Pemberton, R.W. (2007) Does enemy release matter for invasive plants? evidence from a comparison of insect herbivore damage among invasive, non-invasive and native congeners. Biological Invasions, 9, 773-781. 
322

323

324

325

326

327

328

329

330

331

332
Lombardero, M.J., Vázquez-Mejuto P. \& Ayres, M.P. (2008) Role of Plant Enemies in the Forestry of Indigenous vs. Nonindigenous Pines. Ecological Applications, 18, 1171-1181.

McPheron, B.A., Smith, D.C. \& Berlocher, S.H. (1988) Genetic differences between host races of Rhagoletis pomonella. Nature, 336, 64-66.

Meijer, K., Zemel, H., Chiba, S., Smit, C., Beukeboom, L.W. \& Schilthuizen, M. (2015) Phytophagous Insects on Native and Non-Native Host Plants: Combining the Community Approach and the Biogeographical Approach PLoS ONE 10, e0125607.

Memmott, J., Fowler, S.V., Paynter, Q., Sheppard, A.W. \& Syrett, P. (2000) The invertebrate fauna on broom, Cytisus scoparius, in two native and two exotic habitats. Acta Oecologica, 21, 213-222.

Menken, S.B.J. (1996) Pattern and process in the evolution of insect-plant associations: Yponomeuta as an example. Entomologia Experimentalis et Applicata, 80, 297-305.

Miller, J. \& Wenzel, J.W. (1995) Ecological characters and phylogeny. Annual Review of Entomology, 40, 389-415.

Moore, R.J. (1975) The biology of Canadian weeds: 13. Cirsium arvense (L) Scop. Canadian Journal of Plant Science, 55, 1033-1048.

Moran, V.C. (1980) Interactions between phytophagous insects and their Opuntia hosts. Ecological Entomology, 5, 153-164.

Morrow, P.A. \& Lamarche, V.C. (1978) Tree ring evidence for chronic insect suppression of productivity in subalpine Eucalyptus. Science, 201, 1244-1246.

Novotny, V., Miller, S.E., Cizek, L., Leps J., Janda, M., Basset, Y., Weiblen, G.D. \& Darrow, K. (2003) Colonising aliens: caterpillars (Lepidoptera) feeding on Piper aduncum and $P$. umbellatum in rainforests of Papua New Guinea. Ecological Entomology, 28, 704-716.

Proches, S., Wilson, J.R.U., Richardson, D.M. \& Chown, S.L. (2008) Herbivores, but not other insects, are scarce on alien plants. Austral Ecology, 33, 691-700.

Radho-Toly S., Majer J.D. \& Yates C. (2001) Impact of fire on leaf nutrients, arthropod fauna and herbivory of native and exotic eucalypts in Kings Park, Perth, Western Australia. Austral Ecology, 26, 500-506.

Schilthuizen, M., Pimenta, L.P.S., Lammers, Y., Steenbergen, P.J., Flohil, M., Beveridge, N.G., van Duijn, P.T., Meulblok, M.M., Sosef, N. \& van de Ven, R. (2016). Incorporation of an invasive plant into a native insect herbivore food web. PeerJ, 4, e1954.

Schutzenhofer, M.R., Valone, T.J. \& Knight, T.M. (2009) Herbivory and population dynamics of invasive and native Lespedeza. Oecologia, 161, 57-66.

Southwood, T.R.E., Moran, V.C. \& Kennedy, C.E.J. (1982) The richness, abundance and biomass of the arthropod communities on trees. Journal of Animal Ecology, 51, 635-649.

Southwood, T.R.E., Wint, G.R.W., Kennedy, C.E.J. \& Greenwood S.R. (2004) Seasonality, abundance, species richness and specificity of the phytophagous guild of insects on oak (Quercus) canopies. European Journal of Entomology, 101, 43-50. 
360

361

362

363

364

365

Strong, D.R., Lawton, J.H. \& Southwood, T.R.E. (1984) Insects on plants: community patterns and mechanisms. Harvard University Press, Cambridge, Mass.

Sugiura, S. (2010) Associations of leaf miners and leaf gallers with island plants of different residency histories. Journal of Biogeography, 37, 237-244.

Szentesi, A. (1999) Pre-dispersal seed predation of the false indigo, Aporpha fructicosa $\mathrm{L}$. in Hungary. Acta Zoologica Academiae Scientiarum Hungaricae, 45, 125-141.

Tewksbury, L., Casagrande, R., Blossey, B., Hafliger, P. \& Schwarzlander, M. (2002) Potential for biological control of Phragmites australis in North America. Biological Control, 23, 191-212.

Thompson, J.N. (1994) The coevolutionary process. University of Chicago Press, Chicago.

Torchin, M.E., Lafferty, K.D., Dobson, A.P., McKenzie, V.J. \& Kuris, A.M. (2003) Introduced species and their missing parasites. Nature, 421, 628-630.

Viechtbauer, W. (2010) Conducting meta-analyses in R with the metafor package. Journal of Statistical Software, 36, 1-48.

Vilà, M., Maron, J.L. \& Marco, L. (2005) Evidence for the enemy release hypothesis in Hypericum perforatum. Oecologia, 142, 474-479.

Waloff, N. (1966) Scotch broom (Sarothamnus scoparius (L) Wimmer) and its insect fauna introduced into Pacific Northwest of America. Journal of Applied Ecology, 3, 293-311.

Williamson, M.H. (1996) Biological invasions. Chapman \& Hall, London.

Wilson, C.G. \& Flanagan, G.J. (1990) The phytophagous insect fauna of the introduced shrubs Sida acuta Burm.f. and Sida cordifolia L. in the Northern Territory, Australia. Australian Entomological Magazine, 17, 7-15.

Wilson, C.G., Flanagan, G.J. \& Gillett, J.D. (1990) The phytophagous insect fauna of the introduced shrub Mimosa pigra in Northern Australia and its relevance to biological control. Environmental Entomology, 19, 776-784.

Wolfe, L.M. (2002) Why alien invaders succeed: support for the escape-from-enemy hypothesis. The American Naturalist, 160, 705-11.

Yela, J.L. \& Lawton, J.H. (1997) Insect herbivore loads on native and introduced plants: a preliminary study. Entomologia Experimentalis et Applicata, 85, 275-279.

Zuefle, M.E. (2006) The impact of non-native woody plants on the native herbivorous insect community of Northern Delaware. MSc thesis, University of Delaware, Delaware.

Zuefle, M.E., Brown, W.P. \& Tallamy, D.W. (2008) Effects of non-native plants on the native insect community of Delaware. Biological Invasions, 10, 1159-1169. 
392 Tables and figures 


\begin{tabular}{|c|c|c|c|c|}
\hline \multicolumn{2}{|c|}{ Dataset and reference } & $\begin{array}{l}\text { Sample size } \\
\text { (native/non- } \\
\text { native plants) }\end{array}$ & $\begin{array}{l}\text { Mean difference } \\
\text { insect diversity } \\
\text { (native - non- } \\
\text { native) }\end{array}$ & $\begin{array}{l}\text { Standardized } \\
\text { mean diff. insect } \\
\text { diversity }[ \pm 95 \% \\
\text { CI] }\end{array}$ \\
\hline \multicolumn{5}{|c|}{ Community approach } \\
\hline 1 & Agrawal et al. (2005) & $14 / 14$ & 0.11 & $0.08[-0.66,0.82]$ \\
\hline 2 & $\begin{array}{l}\text { Auerbach and Simberloff } \\
\text { (1988) }\end{array}$ & $1 / 2$ & 4.00 & \\
\hline 3 & Burki and Nentwig (1997) & $1 / 1$ & 0.00 & \\
\hline 4 & Engelkes et al. (2012) & $2 / 2$ & 36.60 & $0.68[-1.33,2.70]$ \\
\hline 5 & Gossner et al. (2005) & $1 / 1$ & -5.00 & \\
\hline 6 & Gossner et al. (2007) & $4 / 2$ & 0.07 & $0.48[-1.24,2.20]$ \\
\hline 7 & Hartly et al. (2010) & $3 / 1$ & 6.61 & \\
\hline 8 & Harvey et al. (2015) & $5 / 5$ & 0.01 & $0.05[-1.19,1.29]$ \\
\hline 9 & Helden et al. (2012) & $16 / 7$ & 1.39 & $0.51[-0.39,1.41]$ \\
\hline 10 & Jobin et al. (1996) & $1 / 1$ & 33.00 & \\
\hline 11 & $\begin{array}{l}\text { Kennedy and Southwood } \\
\text { (1984) }\end{array}$ & $21 / 7$ & 12.62 & $1.08[0.18,1.99]$ \\
\hline 12 & Leather (1986) & $46 / 13$ & 14.11 & $0.44[-0.19,1.06]$ \\
\hline 13 & Liu et al. (2006) & $2 / 4$ & 4.00 & $1.38[-0.49,3.24]$ \\
\hline 14 & Meijer et al. (2015) & $8 / 20$ & 0.31 & $0.79[-0.06,1.63]$ \\
\hline 15 & Meijer et al. (2015) & 19 / 19 & 0.40 & $0.50[-0.15,1.14]$ \\
\hline 16 & Novotny et al. (2003) & $1 / 2$ & -0.82 & \\
\hline 17 & Proches et al. (2008) & $3 / 9$ & 2.26 & $1.02[-0.35,2.38]$ \\
\hline 18 & Radho-Toly et al. (2001) & $2 / 2$ & 0.80 & $1.77[-0.54,4.08]$ \\
\hline 19 & Southwood et al. (1982) & $4 / 2$ & 44.75 & $2.30[0.16,4.44]$ \\
\hline 20 & Southwood et al. (1982) & $3 / 3$ & 14.00 & $1.33[-0.44,3.10]$ \\
\hline 21 & Southwood et al. (2004) & $2 / 2$ & 130.5 & $1.46[-0.75,3.67]$ \\
\hline \multirow[t]{2}{*}{22} & Sugiura (2010) & $102 / 49$ & 0.45 & $0.77[0.42,1.13]$ \\
\hline & RE model & $261 / 168$ & & $0.67[0.46,0.89]$ \\
\hline \multicolumn{5}{|c|}{ Biogeographical approach } \\
\hline 23 & Cripps et al. (2006) & 1 & 33.0 & \\
\hline 24 & Goeden (1974) & 1 & 18.0 & \\
\hline 25 & Meijer et al. (2015) & 2 & 0.96 & $0.66[-1.35,2.68]$ \\
\hline 26 & Meijer et al. (2015) & 12 & 0.31 & $0.31[-0.49,1.12]$ \\
\hline
\end{tabular}




\begin{tabular}{|l|l|l|l|l|}
\hline 27 & Memmott et al. (2000) & 2 & 11.0 & $\mathbf{3 . 1 0}[\mathbf{0 . 1 9 , 6 . 0 1 ]}$ \\
\hline 28 & Moore (1975) & 1 & 2.0 & \\
\hline 29 & Southwood et al. (1982) & 2 & 51.5 & $\mathbf{4 . 6 4}[\mathbf{0 . 8 7 , 8 . 4 0 ]}$ \\
\hline 30 & Southwood et al. (2004) & 1 & 8.0 & \\
\hline 31 & Szentesi (1999) & 1 & 9.0 & \\
\hline 32 & Wilson and Flanagan (1990) & 1 & 42.0 & \\
\hline 33 & Wilson et al. (1990) & 1 & 19.0 & \\
\hline & RE model & $\mathbf{2 5}$ & & $\mathbf{1 . 5 9}[-\mathbf{- 0 . 1 9 - 3 . 3 7 ]}$ \\
\hline
\end{tabular}

393 Table 1: Overview of datasets on the differences in insect diversity between native and non-native 394 plants using the community (1-22) or the biogeographical approach (23-33). Indicated are for each dataset the plant sample size (number of native / non-native plant species), the mean difference in insect diversity (number of species), and the standardized mean difference in insect diversity $[ \pm 95 \%$ confidence interval]. Overall outcome of random effects $(\mathrm{RE})$ model indicated in italics. Significant differences are indicated in bold. 


\begin{tabular}{|c|c|c|c|c|}
\hline \multicolumn{2}{|c|}{ Dataset and reference } & $\begin{array}{l}\text { Sample size } \\
\text { (native/non- } \\
\text { native plants) }\end{array}$ & $\begin{array}{l}\text { Mean difference } \\
\text { in insect load } \\
\text { (native - non- } \\
\text { native) }\end{array}$ & $\begin{array}{l}\text { Standardized } \\
\text { mean diff. [ } \pm \\
95 \% \mathrm{CI}]\end{array}$ \\
\hline \multicolumn{5}{|c|}{ Community approach } \\
\hline 34 & $\begin{array}{l}\text { Auerbach and Simberloff } \\
\text { (1988) }\end{array}$ & $1 / 2$ & 10.77 & \\
\hline 35 & Cincotta et al. (2008) & $1 / 1$ & 10.0 & \\
\hline 36 & Gossner et al. (2005) & $1 / 1$ & -557.0 & \\
\hline 37 & Gossner et al. (2007) & $4 / 2$ & 0.25 & $0.60[-1.14,2.33]$ \\
\hline 38 & Harvey et al. (2015) & $5 / 5$ & -0.04 & $\begin{array}{l}-0.20[-1.45, \\
1.04]\end{array}$ \\
\hline 39 & Helden et al. (2012) & $16 / 7$ & 2.28 & $0.60[-0.30,1.51]$ \\
\hline 40 & Meijer et al. (2015) & $8 / 20$ & 1.58 & $1.10[0.23,1.97]$ \\
\hline 41 & Meijer et al. (2015) & 19 / 19 & 3.79 & $0.30[-0.34,0.94]$ \\
\hline 42 & Meijer, unpublished data & $8 / 4$ & 0.57 & $0.13[-1.07,1.34]$ \\
\hline 43 & Novotny et al. (2003) & $1 / 2$ & -0.15 & \\
\hline 44 & Southwood et al. (1982) & $4 / 2$ & $4,902.3$ & $0.56[-1.17,2.28]$ \\
\hline 45 & Southwood et al. (1982) & $3 / 3$ & 294.7 & $1.01[-0.69,2.71]$ \\
\hline 46 & Yela and Lawton (1997) & $8 / 3$ & 17.54 & $0.08[-1.25,1.41]$ \\
\hline \multirow[t]{2}{*}{47} & $\begin{array}{l}\text { Zuefle et al. (2008), Zuefle } \\
\text { (2006) }\end{array}$ & $15 / 30$ & -106.2 & $-0.46[-1.08,0.17]$ \\
\hline & RE model & 91 / 97 & & $0.29[-0.11,0.17]$ \\
\hline \multicolumn{5}{|c|}{ Biogeographical approach } \\
\hline 48 & Fenner and Lee (2001) & 13 & 4.43 & $0.67[-0.12,1.46]$ \\
\hline 49 & Meijer et al. (2015) & 2 & -3.35 & $\begin{array}{l}-0.34[-2.32, \\
1.63]\end{array}$ \\
\hline 50 & Meijer et al. (2015) & 12 & 8.58 & $0.57[-0.24,1.39]$ \\
\hline \multirow[t]{2}{*}{51} & Southwood et al. (1982) & 2 & $11,090.5$ & $0.96[-1.11,3.02]$ \\
\hline & RE model & 29 & & $0.58[0.05,1.10]$ \\
\hline
\end{tabular}

Table 2: Overview of datasets on the differences in insect load (number of insect individuals) between native and non-native plants using the community (34-47) or the biogeographical approach (48-51). Indicated are for each dataset the plant sample size (number of native / nonnative plant species), the mean difference in insect diversity (number of species), and the 
403 standardized mean difference in insect diversity [ $\pm 95 \%$ confidence interval]. Overall outcome of 404 random effects (RE) model indicated in italics. Significant differences are indicated in bold. 


\begin{tabular}{|c|c|c|c|c|}
\hline \multicolumn{2}{|c|}{ Dataset and reference } & $\begin{array}{l}\text { Sample size } \\
\text { (native/non- } \\
\text { native plants) }\end{array}$ & $\begin{array}{l}\text { Mean difference } \\
\text { in herbivore } \\
\text { level (native - } \\
\text { non-native) }\end{array}$ & $\begin{array}{l}\text { Standardized } \\
\text { mean diff. }[ \pm \\
95 \% \mathrm{CI}]\end{array}$ \\
\hline \multicolumn{5}{|c|}{ Community approach } \\
\hline 52 & Agrawal and Kotanan (2003) & $15 / 15$ & -1.66 & $-0.17[-0.89,0.54]$ \\
\hline 53 & $\begin{array}{l}\text { Carpenter and Cappuccino } \\
\text { (2005) }\end{array}$ & 30 / 39 & 1.20 & $0.61[0.12,1.10]$ \\
\hline 54 & Cincotta et al.(2008) & $1 / 1$ & -1.16 & \\
\hline 55 & Harvey et al. (2015) & $5 / 5$ & 0.08 & $1.11[-0.22,2.45]$ \\
\hline 56 & Heard and Sax (2013) & $6 / 6$ & -17.23 & $-2.31[-3.77,-0.85$ \\
\hline 57 & Hill and Kotanen (2010) & $20 / 15$ & 0.62 & $0.77[0.09,1.47$ \\
\hline 58 & Lieurance and Cipollini (2013) & $1 / 1$ & 19.73 & \\
\hline 59 & Liu et al. (2007) & $2 / 1$ & 0.06 & \\
\hline 60 & Liu et al. (2007) & $2 / 4$ & 0.14 & $\begin{array}{l}10.28[4.22, \\
16.34]\end{array}$ \\
\hline 61 & Lombardero et al. (2008) & $1 / 1$ & 12.60 & \\
\hline 62 & Meijer et al. (2015) & $6 / 11$ & 6.55 & $0.6[-0.41,1.62]$ \\
\hline 63 & Meijer et al. (2015) & $12 / 4$ & 2.47 & $0.61[-0.54,1.76]$ \\
\hline \multirow[t]{2}{*}{64} & Schutzenhofer et al. (2009) & $1 / 1$ & 9.08 & \\
\hline & RE model & $102 / 104$ & & $0.91[-1.89,3.70]$ \\
\hline \multicolumn{5}{|c|}{ Biogeographical approach } \\
\hline 65 & Adams et al. (2008) & 1 & 5.02 & \\
\hline 66 & Cripps et al. (2010) & 1 & 25.80 & \\
\hline 67 & Vilà et al. (2005) & 1 & 19.79 & \\
\hline 68 & Wolfe (2002) & 1 & 24.00 & \\
\hline
\end{tabular}

Table 3: Overview of datasets on the differences in level of herbivory between native and nonnative insects, using the community (52-64) or the biogeographical approach (65-68). Indicated are for each dataset the plant sample size (number of native / non-native plant species), the mean difference in insect diversity (number of species), and the standardized mean difference in insect diversity $[ \pm 95 \%$ confidence interval]. Overall outcome of random effects $(\mathrm{RE})$ model indicated in italics. Significant differences are indicated in bold. 
411 Figure 1: Forest plots of the standardized mean differences of the number of insect species (a), 412 the number of insect individuals (b) and level of herbivory (c) for all studies with sample sizes $>$ 413 1. The study numbers are shown at the y-axis, and details about the studies can be found in Tables 414 1-3. RE: random-effects model. Values which are lower than zero, zero or higher than zero, 415 respectively, indicate lower, equal or higher numbers on native than on non-native plants.

416 Diamonds not overlapping the zero line indicate significant differences of the overall random 417 effects (RE) model. 

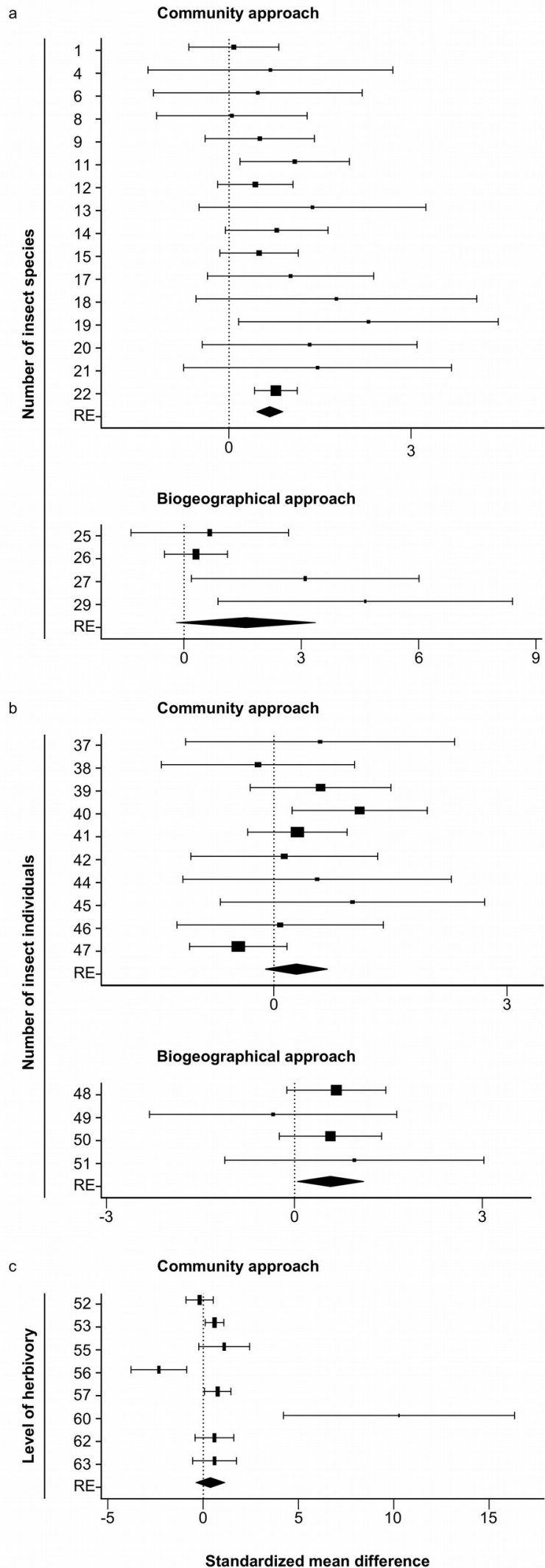